\title{
ОСОБЕННОСТИ ТЕЧЕНИЯ ДЕТСКОГО МУЛЬТИСИСТЕМНОГО ВОСПАЛИТЕЛЬНОГО СИНДРОМА, ВЫЗВАННОГО НОВОЙ КОРОНАВИРУСНОЙ ИНФЕКЦИЕЙ (COVID-19) НА ФОНЕ ДЕКОМПЕНСАЦИИ САХАРНОГО ДИАБЕТА 1 ТИПА И ОСТРОЙ ПОЧЕЧНОЙ НЕДОСТАТОЧНОСТИ. ОПИСАНИЕ КЛИНИЧЕСКОГО СЛУЧАЯ
}

\author{
А.Н. Ташкова, И.В. Гунбина, К.А. Климова \\ ГБУз ЧОДКБ, Россия, г. Челябинск
}

В настоящее время есть сведения, что новая коронавирусная инфекция COVID-19 имеет больше легких и бессимптомных форм в детской популяции. С марта 2020 г. из ряда европейских стран и США стали поступать сообщения о детях с новым заболеванием, имеющим признаки болезни Кавасаки (БК) и синдрома токсического шока (СТШ), получившим одно из названий - детский мультисистемный воспалительный синдром (ДМВC), ассоциированный с COVID-19.

ЦЕЛЬ - описать клинический случай манифестации детского мультисистемного воспалительного синдрома ассоциированного с новой коронавирусной инфекцией на фоне декомпенсации сахарного диабета 1 типа с развитием острой почечной недостаточности.

МАТЕРИАЛЫ И МЕТОДЫ. Проанализирована история болезни пациентки Н., наблюдавшейся с диагнозом Сахарный диабет 1 тип, находившейся на лечении в Государственном бюджетном учреждении здравоохранения «Челябинская областная детская клиническая больница» в 2021 г.

РЕЗУЛЬТАТЫ. Девочка Н, 16 лет, 06.01.2021 г экстренно поступила в отделение реанимации и интенСИвНой терапии ГБУЗ ЧОДКБ.

ДАННЫЕ АНАМНЕЗА. Манифестация СД1 классическая кетоацидозом. Стаж заболевания 2,5 года. Постоянно получала инсулинотерапию в режиме МИИ (инсулин аспарт, детемир - в суточной дозе 0,6 ед/кг). Гликированный гемоглобин 9,7\%. Гликемический контроль неудовлетворительный, ежегодная декомпенсация, на фоне нарушения введения инсулина, пропусков инъекций, ошибок в подсчете XE и нарушения диеты. Последняя декомпенсация в сентябре 2020 года, кетоацидоз. Настоящее ухудшение 05.01.2021 - связано с нарушением режима инсулинотерапии (ребенок не регулярно выполнял инъекции инсулина в течение 2 нед). Жалобы на многократную рвоту, головную боль, нарушение сознания. Экстренно госпитализированы в ГБ г. Миасс, на инфузионную терапию, инсулинотерапию незначительная положительная динамика, эвакуирована в ГБУз ЧОДКБ в отделение реанимации и интенсивной терапии по тяжести состояния. Эпидемиологический анамнез: контакт с бабушкой, которая, перенесла COVID-19 с КT-признаками пневмонии и поражением легочной паренхимы 28\%.

СТАТУС ПРИ ПОСТУПЛЕНИИ. Состояние крайне тяжелое, обусловленное метаболическими нарушениями, комой II. Оценка по Глазго 8 баллов. На осмотр реакции не было. Сохранена болевая чувствительность. Резкий запах ацетона в выдыхаемом воздухе. Кожные покровы бледные, ячеистые, сухие. Конечности холодные на ощупь. Одышка смешанного характера, чД 36 в минуту, аускультативно дыхание жесткое, хрипов нет. Сердечные тоны приглушены, тахиаритмия. ЧСС 103 в минуту. Живот мягкий, безболезненный. Печень до 2 см из под края ребра. Стула не было. Диурез снижен (темп диуреза 1,8-0,5 мл/кг/час). При лабораторном обследовании: в общем анализе крови-лейкоцитоз до 38,5×10 9 с выраженным нейтрофилезом до 78\%, СОЭ 25 мм/ч. Повышение креатинина - 123 мкмоль/л, СРБ - 12,78 мг/л. КЩС: pН 6,73, рСО2 14,9, глюкоза крови 35 ммоль/л, гематокрит 57\%, ВЕ - 29,7, Калий 5,94 ммоль/л, натрий 165ммоль/л, кальций ион 1,93 ммоль/л, Хлор 117 ммоль/л. В общем анализе мочи: белок - 0,33 г/л, л - 2-3 в п/зр., эр. - более 100 в п/зр., сахар - 112 ммоль/л, ацетон — 5 ммоль/л. ЭКГ - умеренная синусовая тахикардия с ЧСС 107 в мин. Удлиненный интервал QТ. УЗИ органов брюшной полости, почек - диффузные изменения печени, паренхимы почек. Размеры поджелудочной железы меньше возрастной нормы.

При допплерографии в бассейне сегментарных ветвей почечных артерий регистрируется нормоскоростной норморезистентный кровоток.

Рентгенография органов грудной клетки - данных за воспалительный и специфический процесс нет. КТ органов грудной клетки - КТ-признаков патологии органов грудной полости не выявлено. 


\section{СБОРНИК ТЕЗИСОВ}

XVII Российская научно-практическая конференция детских эндокринологов «Достижения науки в практику детского эндокринолога»

Обследована на COVID-19: ПЦР мазка из носоглотки - PHK SARS-CoV-2 не обнаружено (взят дважды), при серологическом исследовании выявлены специфические IgM, IgG, свидетельствующие о наличии инфекции.

Н 9-е сутки пребывания в ОРИТ состояние ребенка с отрицательной динамикой, тяжелое, сохранялся метаболический ацидоз, пастозность век, кистей, стоп, боли в животе, отрицательный диурез, геморрагическая сыпь в области груди. Зарегистрирована отрицательная динамика лабораторных показателей- повышение амилазы (100 е/л), СРБ (19,64 мг/л), креатинина (306 ммоль/л), мочевины (21,34 мкмоль/л), повышение уровня прокальцитонина (> 10 нг/мл), Д-димера (2694нг/мл), ферритин 446,8мкг/л, тяжелая анемия (снижение эритроцитов до 1,8, уровня гемоглобина крови до 58 г/л), гипоальбуминемия (общий белок 42 г/л, альбумин 24 г/л), по УзИ органов брюшной полости свободная жидкость в малом тазу объемом до 130 мл. При УзДГ сосудов почек снижение скоростных показателей на уровне сегментарных и междольковых почечных артерий.

На 13-е сутки выраженный болевой синдром - боль в нижних конечностях, в области тазобедренных суставов, передней поверхности бедер и голеней, (ребенок был не в состоянии самостоятельно передвигаться).

На 29-е сутки пребывания в стационаре появление капель алой крови в конце дефекации на фоне оформленного стула.

Учитывая данные эпидемиологического анамнеза, результаты обследования на SARS-COV-2, изменения в клинических и биохимических анализах крови выставлен диагноз: Сахарный диабет 1 тип, декомпенсация. Диабетическая кома. Диабетическая симметричная моторно-сенсорная полинейропатия, энцефалопатия. Мультисистемный воспалительный синдром, ассоциированный с COVID-19. Вторичный артрит, полиартрит. Пролапс митрального клапана 1 степени, с регургитацией 0-1 степени. Открытое овальное окно. Кардиомиопатия. Острая почечная недостаточность, полиурическая стадия.

Проводилось следующее лечение: антибактериальная терапия (цефтриаксон 2,0 /сут, меропенем 12 мг/кг каждые 8 ч), противовирусная терапия (Арпефлю 200 мг каждые 6 ч), гормональная терапия (метипред 150 мг/сут, с постепенной титрацией дозы в течение 4 нед), симптоматическая терапия (гепарин, фрагмин, цитофлавин, омепразол, де-нол, алмагель), инсулинотерапия (аспарт 0,05 Ед/кг/ч в/в микроструйно, коррекция дозы под контролем гликемии), почечная заместительная терапия - 5 сеансов гемодиафильтрации, трансфузионная терапия (эритроцитарная взвесь, 10\% альбумин из расчета 10 мл/кг в/в капельно медленно). На фоне терапии состояние ребенка с положительной динамикой, метаболический ацидоз и электролитные нарушения купированы, темп диуреза восстановлен, достигнуты целевые показатели гликемии, на фоне в/в микроструйного введения инсулина ультракороткого действия со средней скоростью 0,05-0,1 ед/кг/ч, затем базисно-болюсный режим под контролем гликемии.

Девочка и бабушка повторно обучены в школе самоконтроля, выписана в компенсированном состоянии, рекомендовано наблюдение семьи социальной службой.

Таким образом, при бессимптомном или легком течении COVID 19, некомпенсированный сахарный диабет 1 типа является фактором риска развития мультисистемного воспалительного синдрома. Пациентка, нуждается в катамнестическом наблюдении.

Не смотря на то что в большинстве случаев новая коронавирусная инфекция у детей протекает в легкой и бессимптомной форме это не должно снижать настороженности в отношении сочетания данных заболеваний, поскольку диабет отнесен к факторам коморбидного риска. Кроме того при длительно не компенсированном течении сахарного диабета повышается риск присоединения интеркуррентных вирусных и бактериальных заболеваний, повышается вероятность развития кетоацидотической декомпенсации, а тяжелых и критических форм инфекции. Следовательно, при обсуждении особенностей новой коронавирусной инфекции COVID-19 у детей, страдающих СД, необходимо не только оценивать тяжесть и прогноз инфекционного процесса, но и в качестве самостоятельного фактора рассматривать степень метаболической компенсации диабета с планированием рекомендаций по ее достижению для каждого конкретного пациента. 